\title{
Family History of Cancer and Smoking Cessation, Is There a Role for Physicians?
}

\author{
Wenbin Liang*, Tanya Chikritzhs \\ National Drug Research Institute, Curtin University, Perth, Australia. \\ Email: *w.liang@curtin.edu.au \\ Received October $20^{\text {th }}, 2011$; revised November $28^{\text {th }}, 2011$; accepted December $24^{\text {th }}, 2011$
}

\begin{abstract}
Aim: This study aims to investigate the relationships among family history of cancer, physician's advice on quitting, and motivation to quit among smokers in the United State. Method: This study using data collected by the $2010 \mathrm{Na}-$ tional Health Interview Survey. Five separate sets of multivariate logistic regression models were used to investigate the three-direction relationships among: 1) effect of family cancer history on medical doctors' advice on quitting; 2) effect of family cancer history on motivation to quit smoking; 3) effect of doctor's advice on smokers' motivation to quit. Results: Smoking cessation advice given by physicians has a significant effect on both smoker's motivation and action taken to quit smoking, but a large proportion of the smokers with family cancer history did not receive doctor's advice on quitting. Conclusion: Family history of lung cancer or other cancer types was not found to be associated with increased motivation to quit smoking. This is at least partly due to poor collection of family cancer history by physicians. This may be ameliorated by promoting the use of a recently developed self-administered tool for the collection of patient data on family cancer history in primary care settings.
\end{abstract}

Keywords: Primary Care; Family History; Oncology; Smoking Cessation

\section{Introduction}

Tobacco smoking causes various types of cancer, including cancers of the lung, throat, mouth, nasal cavity, esophagus, stomach, pancreas, kidney, bladder, cervix and acute myeloid leukemia [1,2]. The carcinogenic effects of smoking are preventable though smoking cessation [3], and the promotion of smoking cessation is an irreplaceable cancer prevention measure in today's world. However, exposure to tobacco smoke alone is not a sufficient condition to cause cancer (i.e. a large proportion of life-long smokers do not have cancers over their life time). Multiple cumulative mutational steps are required to complete the progression of a malignant tumor [4], tobacco smoke exposure would have to interact with other component causes of cancer including genetic susceptibility, carcinogenic environmental and dietary factors, and other carcinogenic exposures in order to accumulate all the required carcinogenic steps. In smokers, the presence of multiple cancer risk factors increases cancer risk further $[3,5,6]$. A positive family cancer history can be used to identify patients with clusters of genetic, environmental, and behavioral risk factors [7]. Smokers who have first degree relatives with a cancer diagnosis and who understand that such history indicates

${ }^{*}$ Corresponding author. higher cancer risk for themselves, may become motivated to quit as the personal relevance of risk is heightened [8]. To reduce cancer risk among smokers with a family cancer history and to promote smoke cessation, it is important to promote the awareness of cancer risk associated with family history of cancer - physicians in primary care settings are well placed to motivate these patients to quit smoking [9-11]. To perform smoking intervention using a patient's family cancer history requires the physician to routinely collect details of family history of disease but this can be very time consuming, and is usually ignored in practice [12-14]. This study aims to investigate the relationships among family history of cancer, physician's advice on quitting, and motivation to quit among smokers using data collected by the 2010 National Health Interview Survey.

\section{Method}

Data used in this study was collected by the $2010 \mathrm{Na}$ tional Health Interview Survey (NHIS). The NHIS is a multi-purpose health survey conducted by the National Center for Health Statistics to provide estimations on various health parameters of the American population [15]. Details of survey design and procedure can be found http://www.cdc.gov/nchs/nhis.htm. In the family 
history section of the NHIS, sampled adults were asked to provide information on positive cancer history and cancer types for first degree relatives including biological parents and full siblings.

The present study codes cancer history into three categories: 1) without cancer history; 2) with positive cancer history; 3) with positive lung cancer history for fathers, mothers and full siblings separately. The tobacco section of the NHIS collected information on current smoking status from every sampled adult $(+18 \mathrm{yrs})$, and for current smokers, information on smoking cessation were collected.

In this study current smokers are defined as participants who had ever smoked at least 100 cigarettes, and were smoking daily or less often at the time of survey.

Current smokers who had seen a medical doctor in the last 12 months were asked whether in the last 12 months, he or she was advised by a physician to quit smoking. Responses to these questions were used to determine whether a participant had received advice on quitting from a medical practitioner.

Current smokers were asked whether they would like to completely quit smoking cigarettes. Responses to this question were used to define whether a participant had motivation to quit or not. Current smokers were also asked whether they had stopped smoking for one or more days in the last 12 months. Responses to this question were used to define whether a participant had tried to quit smoking in the last 12 months.

\section{Data Analysis}

In order to investigate the effect of family history on 1) receiving advice on quitting from a medical doctor and 2) motivation to quit smoking, three separate outcomes were investigated: 1) whether smokers had received advice on quitting from a physician in the last year $(\mathrm{No}=0$;
Yes $=1)$; 2) whether smokers were motivated to quit smoking $(\mathrm{No}=0$; Yes $=1) ; 3)$ whether smokers had tried to quit smoking in the last year $(\mathrm{No}=0 ; \mathrm{Yes}=1)$. To investigate the effect of receiving medical practitioner advice to quit smoking on smokers' motivation to quit, two outcomes were separately investigated: 1) whether smokers had motivation to quit smoking $(\mathrm{No}=0$; Yes $=$ $1)$; and 2) whether smokers had tried to quit smoking in the last year $(\mathrm{No}=0$; Yes $=1)$.

The following demographic variables were controlled for in the multivariate analysis: age, gender, highest education level completed, health insurance cover, marital status and self rated general health status. Given that the outcomes of interest were relatively common $(>20 \%)$, Poisson regression models were used in the analysis. Poisson regression models (with robust estimations of variance) are preferred over Logistic regression models, the former having being validated [16-18]. The outcomes of interest related to slightly different scopes of current smokers and samples missing answers in dependent or independent variables, therefore there were small variations in sample size $(<10 \%)$ for the analyses relating to different outcomes.

\section{Results}

Using a univariate comparison, it was found that physicians were significantly (chi-square test, $\mathrm{p}<0.05$ ) more likely to recommend smoking cessation to smokers whose biological father, mother or one sibling had cancer. However, in the multivariate analysis, physicians were significantly more likely to advise quitting to smokers whose father or mother had lung cancer, but did not appear to be influenced by parental history of other cancer types or cancer history among siblings (Table 1).

Table 1. Effect of family cancer history on quitting advice from physician.

\begin{tabular}{|c|c|c|c|c|c|}
\hline \multirow[b]{2}{*}{ Family cancer history } & \multicolumn{2}{|c|}{ Received advice to quit smoking from physician } & \multirow[t]{2}{*}{ Prevalence rate ratio } & \multicolumn{2}{|c|}{$95 \%$ confidence interval } \\
\hline & No & Yes & & & \\
\hline \multicolumn{6}{|l|}{ Cancer history of full sibling(s) } \\
\hline With cancer & 2394 & 1423 & (base) & & \\
\hline With cancer but not lung cancer & 239 & 232 & 1.03 & 0.94 & 1.14 \\
\hline With lung cancer & 34 & 45 & 1.05 & 0.87 & 1.28 \\
\hline \multicolumn{6}{|l|}{ Cancer history of biological father } \\
\hline With cancer & 2190 & 1297 & (base) & & \\
\hline With cancer but not lung cancer & 388 & 297 & 1.03 & 0.93 & 1.13 \\
\hline With lung cancer & 89 & 106 & 1.23 & 1.08 & 1.40 \\
\hline \multicolumn{6}{|l|}{ Cancer history of biological mother } \\
\hline With cancer & 2223 & 1305 & (base) & & \\
\hline With cancer but not lung cancer & 404 & 340 & 1.07 & 0.98 & 1.17 \\
\hline With lung cancer & 40 & 55 & 1.21 & 1.00 & 1.45 \\
\hline
\end{tabular}


It was observed that in both univariate and multivariate analysis, smokers' parental or siblings' history of cancer did not have a significant effect on their motivation to quit or action taken to quit smoking (Table 2). Combining cancer history from all family members together, the rate ratio (positive family history to negative family history) was 1.04 for motivation to quit and 1.05 for action taken to quit, and both estimations were not significant. Given marginally significant and similar associations were observed between cancer (lung and other types) history of mother and motivation to quit, a further analysis was performed by combing mother history of lung cancer and other cancers types together. A small but significant increased in motivation was observed (relative risk, $95 \%$ confidence interval from multivariate analysis: $1.05,1.002-1.107)$.

Some $39 \%$ of smokers who saw a physician at least once in the last 12 months were advised by their doctors to quit smoking, and among those who received advice on quitting, more than half had stopped smoking for at least one day in the last 12 months. Furthermore recommendation by a medical practitioner to quit smoking was significantly associated with motivation to quit and action taken to quit in both univariate and multivariate analysis (Table 3).

\section{Discussion}

Smoking cessation advice given by physicians has a significant effect on both smoker's motivation and action

Table 2. Effect of family cancer history on smokers' motivations and actions to quit.

\begin{tabular}{|c|c|c|c|c|c|}
\hline \multirow[b]{2}{*}{ Family cancer history } & \multicolumn{2}{|c|}{ Motivation to quit in the last 12 months } & \multirow[t]{2}{*}{ Prevalence rate ratio } & \multicolumn{2}{|c|}{$95 \%$ confidence interval } \\
\hline & No & Yes & & & \\
\hline \multicolumn{6}{|l|}{ Cancer history of full siblings } \\
\hline With cancer & 1170 & 2602 & (base) & & \\
\hline With cancer but not lung cancer & 158 & 306 & 0.96 & 0.90 & 1.04 \\
\hline With lung cancer & 23 & 56 & 1.07 & 0.93 & 1.24 \\
\hline \multicolumn{6}{|l|}{ Cancer history of biological father } \\
\hline With cancer & 1094 & 2356 & (base) & & \\
\hline With cancer but not lung cancer & 196 & 474 & 1.05 & 0.99 & 1.11 \\
\hline With lung cancer & 61 & 134 & 1.01 & 0.91 & 1.11 \\
\hline \multicolumn{6}{|l|}{ Cancer history of biological mother } \\
\hline With cancer & 1115 & 2372 & (base) & & \\
\hline With cancer but not lung cancer & 213 & 521 & 1.05 & 0.99 & 1.10 \\
\hline \multirow[t]{2}{*}{ With lung cancer } & 23 & 71 & 1.11 & 0.99 & 1.25 \\
\hline & \multicolumn{3}{|c|}{ Quit for $\geq 1$ day in the last 12 months } & & \\
\hline \multicolumn{6}{|l|}{ Cancer history of full siblings } \\
\hline With cancer & 2007 & 1808 & (base) & & \\
\hline With cancer but not lung cancer & 249 & 221 & 1.07 & 0.96 & 1.19 \\
\hline With lung cancer & 46 & 33 & 1.01 & 0.78 & 1.31 \\
\hline \multicolumn{6}{|l|}{ Cancer history of biological father } \\
\hline With cancer & 1837 & 1647 & (base) & & \\
\hline With cancer but not lung cancer & 363 & 322 & 1.04 & 0.95 & 1.13 \\
\hline With lung cancer & 102 & 93 & 1.06 & 0.91 & 1.24 \\
\hline \multicolumn{6}{|l|}{ cancer history of biological mother } \\
\hline With cancer & 1850 & 1676 & (base) & & \\
\hline With cancer but not lung cancer & 400 & 343 & 0.99 & 0.91 & 1.08 \\
\hline With lung cancer & 52 & 43 & 1.00 & 0.80 & 1.26 \\
\hline
\end{tabular}


Table 3. Effects of physician's advice on smokers' motivations and actions to quit.

\begin{tabular}{ccccc}
\hline & Quit motivations in the last 12 months & Prevalence rate ratio & $95 \%$ confidence interval \\
\hline Quitting advice from physician & No & Yes & & \\
No & 1015 & 1835 & 1.18 & 1.14 \\
yes & 449 & 1376 & & \\
Quitting advice from physician & Quit $\geq 1$ day in the last 12 months & Yes & & \\
No & 1610 & 1273 & 1.23 \\
yes & 889 & 956 & 1.20 & 1.28 \\
\hline
\end{tabular}

taken to quit smoking. This concurs with observations from previous studies which indicates that doctors' advice appears to be one of the most effective measures for improving smoking cessation rate $[8,9,19]$. However, in practice, a considerable proportion of smokers did not receive any smoking cessation advice from their primary care providers $[20,21]$. This was also confirmed by the current study, with over $60 \%$ of smokers having not received advice on quitting from a medical practitioner in the last 12 months. This suggests that some physicians may themselves lack the motivation or time to enquire about smoking status and/or encourage smoking cessation among their patients and overlook opportunities to identify factors (including family cancer history) that may motivate quitting.

However collecting family history usually is part of the clinical routine, but this can be very brief [12-14]. It was observed that physicians were more likely to advise smoking cessation if the patient had a father or a mother diagnosed with lung cancer, however about $45 \%$ of the smokers with a father and/or a mother with lung cancer did not receive advice on quitting. Moreover there is no effect of full sibling history of lung cancer. This is likely to due to that such family histories were missed out during the consultations. During the day-to-day practice, collecting details of family history of disease is time consuming, and family history may not be directly relevant to the issues of consultations, and therefore usually very brief but far from complete family history of disease is collected by physicians [12-14]. The My Family Health Portrait tool developed and tested by the Centers for Disease Control and Prevention (https://familyhistory. hhs.gov/fhh-web/home.action) may be useful in helping to overcome these barriers by enabling the collection and maintenance up-date family histories of cancer and other diseases in primary care settings prior to consultation (i.e. in the waiting room).

In this study we also observed that the association between smokers' family history of cancer and motivation of smoking cessation was very weak, but as discussed above, smokers with family history of cancer may not be fully aware that their family history is related to their own personal risk of cancer. It has been noted that smokers are unlikely be motivated by factors they do not know or believe to be relevant to them directly [22]. This further highlights the important role that physicians have in informing their patients about the relevance of family cancer histories and motivating their patients to stop smoking.

\section{Conclusion}

Family history of lung cancer or other cancer types was not found to be associated with increased motivation to quit smoking in an American population. This is at least partly due to poor collection of family cancer history by physicians. This may be ameliorated by promoting the use of a recently developed self-administered tool for the collection of patient data on family cancer history in primary care settings.

\section{REFERENCES}

[1] A. J. Sasco, M. B. Secretan and K. Straif, "Tobacco Smoking and Cancer: A Brief Review of Recent Epidemiological Evidence," Lung Cancer, Vol. 45, Supplement 2, 2004, pp. S3-S9.

[2] P. Vineis, M. Alavanja, P. Buffler, E. Fontham, S. Franceschi, Y. T. Gao, P. C. Gupta, A. Hackshaw, E. Matos, J. Samet, F. Sitas, J. Smith, L. Stayner, K. Straif, M. J. Thun, H. E. Wichmann, A. H. Wu, D. Zaridze, R. Peto and R. Doll, "Tobacco and Cancer: Recent Epidemiological Evidence," Journal of the National Cancer Institute, Vol. 96, No. 2, 2004, pp. 99-106. doi:10.1093/jnci/djh014

[3] J. Austoker, D. Sanders and G. Fowler, "Cancer Prevention in Primary Care: Smoking and Cancer: Smoking Cessation," British Medical Journal, Vol. 308, No. 6942, 1994, pp. 1478-1482. doi:10.1136/bmj.308.6942.1478

[4] P. A. Jones and S. B. Baylin, "The Epigenomics of Cancer," Cell, Vol. 128, No. 4, 2007, pp. 683-692. doi:10.1016/j.cell.2007.01.029

[5] J. Steevens, L. J. Schouten, R. A. Goldbohm and P. A. 
van den Brandt, "Alcohol Consumption, Cigarette Smoking and Risk of Subtypes of Oesophageal and Gastric Cancer: A Prospective Cohort Study," Gut, Vol. 59, No. 1, 2010, pp. 39-48. doi:10.1136/gut.2009.191080

[6] M. R. Welfare, J. Cooper, M. F. Bassendine and A. K. Daly, "Relationship between Acetylator Status, Smoking, and Diet and Colorectal Cancer Risk in the North-East of England," Carcinogenesis, Vol. 18, No. 7, 1997, pp. 1351-1354. doi:10.1093/carcin/18.7.1351

[7] P. W. Yoon, M. T. Scheuner, C. Jorgensen and M. J. Khoury, "Developing Family Healthware, a Family History Screening Tool to Prevent Common Chronic Diseases," Preventing Chronic Disease, Vol. 6, No. 1, 2009, pp. 1-11.

[8] J. E. Anderson, D. E. Jorenby, W. J. Scott and M. C. Fiore, "Treating Tobacco Use and Dependence," Chest, Vol. 121, No. 3, 2002, pp. 932-941. doi:10.1378/chest.121.3.932

[9] C. C. Butler, S. Rollnick, D. Cohen, M. Bachmann, I. Russell and N. Stott, "Motivational Consulting versus Brief Advice for Smokers in General Practice: A Randomized Trial," British Journal of General Practice, Vol. 49, No. 445, 1999, pp. 611-616.

[10] G. C. Williams, M. Gagne, R. M. Ryan and E. L. Deci, "Facilitating Autonomous Motivation for Smoking Cessation," Health Psychology, Vol. 21, No. 1, 2002, pp. 4050. doi:10.1037/0278-6133.21.1.40

[11] L. I. Solberg, M. V. Maciosek, N. M. Edwards, H. S. Khanchandani and M. J. Goodman, "Repeated Tobacco-Use Screening and Intervention in Clinical Practice: Health Impact and Cost Effectiveness," American Journal of Preventive Medicine, Vol. 31, No. 1, 2006, pp. 62-71. doi:10.1016/j.amepre.2006.03.013

[12] S. J. Hayflick, M. P. Eiff, L. Carpenter and J. Steinberger, "Primary Care Physicians' Utilization and Perceptions of Genetics Services," Genetics in Medicine, Vol. 1, No. 1, 1998, pp. 13-21. doi:10.1097/00125817-199811000-00005

[13] L. S. Acheson, G. L. Wiesner, S. J. Zyzanski, M. A. Goodwin and K. C. Stange, "Family History-Taking in Community Family Practice: Implications for Genetic Screening," Genetics in Medicine, Vol. 2, No. 3, 2000, pp. 180185. doi:10.1097/00125817-200005000-00004

[14] E. C. Rich, W. Burke, C. J. Heaton, S. Haga, L. Pinsky,
M. P. Short and L. Acheson, "Reconsidering the Family History in Primary Care," Journal of General Internal Medicine, Vol. 19, No. 3, 2004, pp. 273-280. doi:10.1111/j.1525-1497.2004.30401.x

[15] NCHS, "Data File Documentation, National Health Interview Survey," Machine Readable Data File and Documentation 2010, National Center for Health Statistics and Centers for Disease Control and Prevention, Hyattsville, 2011.

[16] T. Behrens, D. Taeger, J. Wellmann and U. Keil, "Different Methods to Calculate Effect Estimates in CrossSectional Studies-A Comparison between Prevalence Odds Ratio and Prevalence Ratio," Methods of Information in Medicine, Vol. 43, No. 5, 2004, pp. 505-509.

[17] L. A. McNutt, C. T. Wu, X. N. Xue and J. P. Hafner, "Estimating the Relative Risk in Cohort Studies and Clinical Trials of Common Outcomes," American Journal of Epidemiology, Vol. 157, No. 10, 2003, pp. 940-943. doi:10.1093/aje/kwg074

[18] L. M. S.Coutinho, M. Scazufca and P. R. Menezes, "Methods for Estimating Prevalence Ratios in Cross-Sectional Studies," Revista de Saúde Pública, Vol. 42, No. 6, 2008.

[19] L. F. Stead, G. Bergson and T. Lancaster, "Physician Advice for Smoking Cessation," Cochrane Database Systematic Reviews, No. 2, 2008, Article No. CD000165.

[20] C. Lopez-Quintero, R. M. Crum and Y. D. Neumark, "Racial/Ethnic Disparities in Report of Physician-Provided Smoking Cessation Advice: Analysis of the 2000 National Health Interview Survey," American Journal of Public Health, Vol. 96, No. 12, 2006, pp. 2235-2239. doi:10.2105/AJPH.2005.071035

[21] A. K. Ferketich, S. Gallus, P. Colombo, R. Fossati, G. Apolone, P. Zuccaro and C. La Vecchia, "Physician-Delivered Advice to Quit Smoking among Italian Smokers," American Journal of Preventive Medicine, Vol. 35, No. 1, 2008, pp. 60-63. doi:10.1016/j.amepre.2008.03.022

[22] E. L. Lykins, L. O. Graue, E. H. Brechting, A. R. Roach, C. G. Gochett and M. A. Andrykowski, "Beliefs about Cancer Causation and Prevention as a Function of Personal and Family History of Cancer: A National, Population-Based Study," Psycho-Oncology, Vol. 17, No. 10, 2008, pp. 967-974. doi:10.1002/pon.1306 